\section{(6) OPEN ACCESS}

PAPER

\title{
Questionable content of an industry-supported medical school lecture series: a case study
}

\author{
Navindra Persaud ${ }^{1,2,3}$
}

\begin{abstract}
${ }^{1}$ Department of Family and Community Medicine, St Michael's Hospital, Toronto, Canada

${ }^{2}$ Keenan Research Centre in the Li Ka Shing Knowledge Institute, St Michael's Hospital, Toronto, Canada

${ }^{3}$ Department of Family and Community Medicine, University of Toronto, Toronto, Canada
\end{abstract}

\section{Correspondence to} Dr Navindra Persaud, St Michael's Hospital, 80 Bond Street, Toronto, Ontario, Canada M5B 1X2; nav.persaud@utoronto.ca

Received 10 January 2013 Revised 12 April 2013 Accepted 21 May 2013 Published Online First 11 June 2013

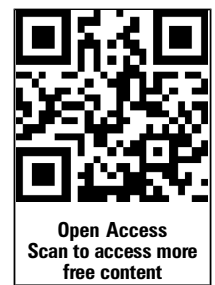

\begin{abstract}
Background Medical schools are grappling with how best to manage industry involvement in medical education.

Objective To describe a case study of industrysupported undergraduate medical education related to opioid analgesics.

Method Institutional case study.

Results As part of their regular curriculum, Canadian medical students attended pain pharmacotherapy lectures that contained questionable content about the use of opioids for pain management. The lectures were supported by pharmaceutical companies that market opioid analgesics in Canada and the guest lecturer was a member of speakers bureaus of the same companies. These conflicts of interests were not fully disclosed. A reference book that reinforced some of the information in the lectures and that was paid for by a sponsoring company was made available to students. This is the first report of an association between industry sponsorship and the dissemination of potentially dangerous information to medical students.

Conclusions This case demonstrates the need for better strategies for preventing, identifying and dealing with problematic interactions between the pharmaceutical industry and undergraduate medical education. These might include the avoidance of unnecessary conflicts of interest, more disclosure of conflicts, an open process for dealing with recognised problems and internationally harmonised conflict of interest policies.
\end{abstract}

Undergraduate medical education is relatively free of restrictions on industry involvement compared with primary research. Whereas researchers must publicly register clinical trials, ${ }^{1}$ apply for independent ethics approval and declare potential conflicts of interest when findings are published, ${ }^{2}$ no universally accepted standards for medical educators exist. Industry involvement in medical education is pervasive, ${ }^{3}{ }^{4}$ and some medical schools in the UK solicit pharmaceutical companies to host lectures. ${ }^{5}$ Many institutions, including most American medical schools, have recently adopted conflict of interest policies pertinent to medical education, ${ }^{6}$ while others are developing them.

The management of conflicts of interest is particularly important for controversial clinical topics where marketing has the potential to shape the later practices of medical students in the absence of a clear evidence base. A notable example is the use of opioids for the management of chronic non-cancer pain. Recent guidelines have highlighted the morbidity associated with chronic pain and the lack of evidence supporting the use of opioids for this indication. ${ }^{78}$ Opioid-related harms have increased in parallel with the increased prescribing during the past decades, with a tripling of opioid-related mortality between 1999 and 2006 in the USA and a similar increase in Canada. ${ }^{9-12}$ Regulatory bodies ${ }^{13}$ and governments ${ }^{14}$ have recognised the need to curb opioid-related harms. Part of the surge in opioid prescribing is thought to be the result of aggressive, misleading and in some cases, admittedly illegal marketing to potential prescribers. ${ }^{15}$

In this article, I describe a case of industrysupported undergraduate medical education related to opioid prescribing in Canada. Instructive aspects are highlighted with the aim of informing the decision-making of educational institutions, industry partners, medical educators and trainees around the world. An analysis of this case will help medical educators to decide when it is appropriate to accept funding for medical educational sessions.

\section{CASE DESCRIPTION}

Since 2004, second-year medical students at a Canadian medical school, together with students from dentistry, nursing, pharmacy, occupational therapy and physical therapy, attended a mandatory week-long curriculum on pain management. (The author of this paper attended the series as a medical student.) The curriculum was organised by a university centre that specialises in pain research and education. Students chose from a menu of didactic sessions, among which were pain pharmacotherapy lectures. A reference book on pain management was also offered to students free of charge.

The pharmacotherapy lectures included information about indications, adverse effects, routes of administration and dosing of commonly used analgesics. In a 'modified WHO analgesic ladder' oxycodone was categorised, along with codeine and tramadol, as a weak opioid (and also as a strong opioid). In fact, oxycodone is (at least 1.5 times) more potent than morphine, ${ }^{16}{ }^{17}$ which was correctly identified as a strong opioid. The original WHO pain ladder (see table 1) was intended to promote effective and cost effective pain management and does not mention oxycodone. ${ }^{18}$

The effectiveness of opioids for chronic noncancer pain was emphasised. In the case-based discussions, all the resolutions involved opioid prescriptions, and trade names of opioid combination products were used. The following quote was 
Table 1 Analgesics listed in the WHO pain ladder and lecture version

\begin{tabular}{llll}
\hline & & WHO pain relief ladder & 'Modified WHO analgesic ladder' \\
\hline Step 1 & Non-opioids \pm adjuvants & Aspirin, paracetamol & Acetaminophen, aspirin, NSAIDS \\
Step 2 & Mild or weak opioids \pm non-opioids \pm adjuvants & Codeine & Tramadol, codeine, oxycodone \\
Step 3 & Strong opioids \pm non-opioids \pm adjuvants & Morphine & Hydromorphone, morphine, oxycodone, fentanyl, methadone, buprenorphine \\
\hline NSAIDs, non-steroidal anti-inflammatory drugs. & &
\end{tabular}

attributed to a Canadian Medical Association Journal review article, ${ }^{19}$ although the sentence does not appear in the paper:

There is now strong consistent evidence that opioids relieve chronic neuropathic and nociceptive pains and improve function in placebo-controlled trials with patients who suffer chronic noncancer pain.

While the cited paper states that "[o]pioids were effective in the treatment of [chronic non-cancer pain] overall" the evidence was not characterised as either 'strong' or 'consistent' in the cited paper and the following cautions were included: "most trials were not long enough to estimate the duration of efficacy of opioids in chronic pain, the potential for opioid tolerance, or long-range adverse effects such as hypogonadism or opioid abuse" and "[m] ost trials that compare opioids with other drugs were not adequately designed as equivalence or noninferiority trials [...] There is a need for well-designed equivalence trials to compare opioids and other drugs." 19 These limitations of the evidence for the use of opioids for non-cancer pain are also discussed in clinical practice guidelines. ${ }^{78}$

The adverse effects of opioids were downplayed. For example, one slide stated that "opioids have never been shown to directly cause organ damage when taken therapeutically" (even though opioids cause organ damage when they produce fatal overdoses), and no studies related to the risks of addiction, misuse or death were cited. The lectures also questioned the efficacy of non-opioid analgesics and emphasised their adverse effects, including reference to a study linking acetaminophen use to cardiovascular events.

The reference book Managing Pain: The Canadian Healthcare Professional's Reference ${ }^{20} 21$ was offered to students free of charge. The content was similar to that of the lectures. The book contained a 'modified WHO analgesic ladder' that listed oxycodone among weak opioids. An earlier edition of that book $^{20}$ touted long-acting opioid formulations as having a 'lower abuse potential' than short-acting formulations. This book is funded and copyrighted by one of the funding pharmaceutical companies and, in some instances, bookmarks displaying trade names of the sponsor's products were tethered to the books.

The university centre that organised the lectures received funding for educational and research activities from several sources, including pharmaceutical companies that sell opioid analgesics. By 2007 the amount of this funding exceeded CAN $\$ 500000 .^{22}$ Pharmaceutical companies supported the development of the educational sessions with at least CAN\$1 17000 of financial contributions between 2002 and 2006. ${ }^{23}$ In some years, but not others, the student course manual disclosed the industry funding sources. The lectures on pharmacotherapy were delivered by a guest speaker who was a speakers bureaus member for some of the same companies. The speaker's conflicts of interest were not disclosed to students in either the course manual or the lecture notes. One of the sponsoring companies paid the production costs of the reference book and this financial support was disclosed in the textbook.

After senior university officials were informed of concerns about the course in 2010, speaker conflict disclosures were instituted and distribution of the textbook ceased. The lectures continued in 2010 and the content was similar to that in previous years. After the 2010 session, the Faculty of Medicine declared that the non-faculty lecturer would no longer teach its students but did not inform previous students of concerns about the content of the lectures or the reference book. After these decisions were made, the university conducted an inquiry that examined the governance of the university body organising the lectures and the handling of industry sponsorship. ${ }^{23}$

\section{DISCUSSION}

Medical students received information about opioids in educational sessions that were developed using funding from pharmaceutical companies that sell opioids. The course material contained information that aligned with the interests of these companies by minimising opioid-related harms relative to those of other analgesics, overstating the evidence for their effectiveness, and in at least one instance, provided a potentially dangerous characterisation of the potency of a commonly used opioid. The information provided in these lectures may have affected patient care, although this has not been demonstrated and all attendees should have received further education about pain management before beginning independent practice. Several lessons can be derived from this case about how to prevent, recognise and deal with potential problems.

\section{How to prevent and recognise potential problems}

Strategies for identifying and preventing potential problems include the education of trainees and educators about avoiding and managing interactions with the pharmaceutical industry, more transparent disclosure procedures and the harmonisation of conflict of interest policies.

Despite good intentions, industry involvement in medical education can cause unrecognised problems. The educational programme in question was well known for promoting interdisciplinary collaboration and it was recognised with a teaching award. Although the organisers did not believe that the content was influenced by sponsorship and referred to industry financial support as 'philanthropic', ${ }^{22}$ for several years the lectures contained statements that promoted the products being sold by sponsors. A non-faculty lecturer with conflicts of interests was invited to give the lectures when faculty members without conflicts were available. It should not come as a surprise that the students attending these sessions also did not recognise the problematic content since even practising physicians often fail do so. ${ }^{24}$ The difficulty in recognising problems underlines the need to identify and avoid potentially problematic sessions before they take place. Box 1 provides a decision aid that can be used to document the interaction between topics that may be subject to pharmaceutical industry influence and conflicts of 
Box 1 Decision aid for avoiding problematic conflicts of interest in undergraduate medical education

1. Topic. Is the information or opinions about the topic likely to be influenced by conflicts of interests?

2. Session conflict of interest. Is third-party (eg, pharmaceutical industry) funding necessary or might the session or materials be delivered without such funding?

3. Educator conflict of interest. Is it necessary to involve educators with conflicts of interest or are qualified educators without conflicts of interest available?

\begin{tabular}{lll}
\hline & Topic unlikely to be influenced & Topic liable to influence \\
No conflicts & Low risk & Moderate risk \\
Conflict present & Moderate risk & - High risk \\
\hline
\end{tabular}

interest. The confluence of a controversial topic involving therapeutics and relevant conflict of interest in this case should have prompted greater attention to this high-risk combination. Note that in this case the content of the course was reportedly reviewed every year by a curriculum committee, yet the problems were not detected or dealt with through this process.

Medical students ${ }^{25}{ }^{26}$ and physicians ${ }^{24} 27$ are unlikely to believe that their views are biased by their interactions with the pharmaceutical industry, but there is evidence that educational interventions are effective at changing this view. ${ }^{28} 29$ Trainees might be more likely to recognise problematic content if they had a taxonomy for describing the spectrum of such content from a selective presentation of correct information to falsehoods. Both didactic and role playing educational sessions can alert medical students to the effects of marketing on clinical decision-making. ${ }^{29}{ }^{30}$ For example, an educational session for second- and third-year medical students comprising a session with a former pharmaceutical representative, a faculty debate and online modules increased scepticism about the appropriateness of pharmaceutical company involvement in teaching. ${ }^{29}$ Such educational sessions can be part of a broader effort to educate trainees about the financial implications of clinical decision-making, ${ }^{31}$ which may include the subtle implications of gift acceptance ${ }^{32-34}$ and the price patients pay for direct physician marketing such as the distribution of 'free' textbooks. ${ }^{35}$

In undergraduate medical education, there may not be a simple strategy to ensure that competing interests are fully disclosed, ${ }^{36-39}$ and this case demonstrates that disclosures are sometimes omitted. One option is to hold information about faculty potential conflicts of interest in a central online repository that is accessible to students. Such a public registry would allow students to determine the conflicts of interest of physicians they meet in clinical settings-there currently is no easy way for students to do this. One medical school already requires public online reporting of conflicts, ${ }^{38}$ and there is another online database listing payments from certain pharmaceutical companies to physicians. ${ }^{40}$ These proofs of concept may encourage other institutions to implement registries and perhaps they might be combined into one central public registry. However, it is also important to recognise the limitations and potentially negative consequences of disclosure that may include moral licensing (the belief that biased advice is justifiable because conflicts have been declared) and strategic exaggeration (the tendency to provide more biased advice to overcome expected scepticism resulting from conflict disclosure). ${ }^{41} 42$ The fact that the industry support for the sessions in this case was referred to as 'unrestricted educational grants' may make one question the meaningfulness of that term and favour the use of neutral terms such as 'funding'. If even industry 'unrestricted educational grants' are associated with inaccuracies, the complete elimination of industry funding from undergraduate medical education may be necessary.

Discussing problematic cases of industry involvement in medical education may increase awareness and reduce the likelihood of reoccurrences. Indeed, this very case might have been prevented if the organisers had been aware of analogous problems elsewhere. Claims not unlike those made in the lectures and the reference book were the subject of investigations into the marketing of opioids in the USA that resulted in fraud convictions. Three executives at the American manufacturer of long-acting oxycodone pleaded guilty to fraud in $2007 .{ }^{13}$ The Agreed Statement of Facts in the guilty plea indicates that some company employees decided not to correct the prevalent misperception that oxycodone was less potent than morphine. ${ }^{4344}$ Also, long-acting oxycodone was touted as having less addiction and abuse potential and being less likely to be diverted compared with other opioid formulations. ${ }^{44}$ That illegal marketing ${ }^{15}$ occurred at the same time as both the dramatic increase in opioid prescriptions and the increase in opioid-related mortality in the USA. ${ }^{9}{ }^{10}$ Opioid prescriptions and opioid-related deaths both also rose in Ontario during the period medical students were exposed to this information in an industry-supported lecture series. ${ }^{11} 12$

This increasing mortality underlines how important it is for trainees and their future patients to be protected from problematic information in undergraduate medical education even as collaborations between universities and industry continue. Yet today the management and monitoring of industry involvement in undergraduate medical education lags behind that in medical research. Policies about industry involvement in undergraduate medical education vary by jurisdiction, do not consistently deal with all important concerns and can be vague. For example, three issues raised by this case are treated differently by current American and Canadian guidelines (table 2). ${ }^{36-39}$ Hopefully this unevenness will soon be replaced by the sort of consistency demonstrated by the large group of medical journals that recently agreed on a uniform conflict of interest disclosure form for authors. ${ }^{2}$ The Institute of Medicine has recommended standardised disclosures and bans on speaker bureau membership and industry gift acceptance. ${ }^{39}$

Existing conflict of interest policies would allow lecture series such as this one to take place at most medical schools. For example, the 10 American medical schools with most stringent conflict of interest policies as rated by the American Medical Student Association in their 'PharmFree Scorecard' could all have hosted a lecture series such as the one discussed here as they allow industry sponsorship of medical school lectures and speakers who receive funding from the same companies. ${ }^{6}$ Box 2 contains a list of questions that can be asked of any institution's conflict of interest policy to determine whether this lecture series would be permitted. Given that the problematic content in this case was not detected for several years, it is plausible that problematic information is being disseminated in other industrysupported teaching sessions at medical schools right now.

\section{What to do when potential problems are identified}

It is important for educators to respond appropriately and promptly once a problem has been identified-especially when patient safety is at stake. The response to these educational 
Table 2 Example guidelines on industry involvement in medical education

\begin{tabular}{|c|c|c|c|}
\hline & Canadian Medical Association* & Association of American Medical Colleges & Stanford Medical School \\
\hline $\begin{array}{l}\text { Gift and reference } \\
\text { book distribution }\end{array}$ & $\begin{array}{l}\text { Practising physicians should not accept } \\
\text { personal gifts of any significant monetary or } \\
\text { other value from industry. Physicians should be } \\
\text { aware that acceptance of gifts of any value has } \\
\text { been shown to have the potential to influence } \\
\text { clinical decision-making. (...) Practising } \\
\text { physicians may accept patient teaching aids } \\
\text { appropriate to their area of practice provided } \\
\text { that these aids carry at most the logo of the } \\
\text { donor company and do not refer to specific } \\
\text { therapeutic agents, services or other products }\end{array}$ & $\begin{array}{l}\text { Academic medical centres should establish and } \\
\text { implement policies that prohibit the acceptance } \\
\text { of any gifts from industry by physicians and } \\
\text { other faculty, staff, students and trainees of } \\
\text { academic medical centres, whether on-site or } \\
\text { off-site }\end{array}$ & $\begin{array}{l}\text { Medical staff, faculty, staff, students, trainees and } \\
\text { employees may not accept gifts from industry } \\
\text { anywhere at the Stanford School of Medicine, } \\
\text { Stanford Hospital and Clinics... It is strongly } \\
\text { advised that no form of personal gift from } \\
\text { industry be accepted under any circumstances }\end{array}$ \\
\hline Trade name usage & $\begin{array}{l}\text { Generic names should be used in addition to } \\
\text { trade names in the course of CME/CPD } \\
\text { activities }\end{array}$ & (No specific mention) & (No specific mention) \\
\hline $\begin{array}{l}\text { Speakers bureaus } \\
\text { membership of } \\
\text { lecturer }\end{array}$ & (No specific mention) & $\begin{array}{l}\text { With the exception of settings in which } \\
\text { academic investigators are presenting results of } \\
\text { their industry-sponsored studies to peers and } \\
\text { there is opportunity for critical exchange, } \\
\text { academic medical centres should strongly } \\
\text { discourage participation by their faculty in } \\
\text { industry-sponsored speakers bureaus }\end{array}$ & $\begin{array}{l}\text { Participation in the following activities is not } \\
\text { permitted: industry-sponsored 'speakers bureaus' } \\
\text { (ie, contractual relationships to give talks in } \\
\text { which the topic(s) and/or content are provided by } \\
\text { the company) }\end{array}$ \\
\hline
\end{tabular}

* The guidelines for CME/CPD events but 'the same principles will also apply for educational events (such as noon-hour rounds and journal clubs) which are held as part of medical or residency training.' The Canadian Medical Association guidelines have been endorsed by the Association of Faculty of Medicine of Canada.

$\mathrm{CME} / \mathrm{CPD}$, continuing medical education/continuing professional development.

'adverse events' might be guided by principles used to deal with clinical misadventure ${ }^{45}$ and include prompt disclosure to those affected as well as corrective measures. Box 3 suggests how these principles might be applied to problematic conflicts of interest in undergraduate medical education. The potential harm to patients related to the presented information in this case can still be mitigated by notifying past students of the problems with the lectures and the reference book that they may still use when making clinical decisions. Medical school conflict of interest policies do not require disclosure of educational misadventure. ${ }^{6}$ Properly handled problems would serve as positive learning opportunities for both trainees and educators.

\section{CONCLUSION}

This case study highlights several policy and practice changes that might reduce the likelihood of similar problems arising again and practices that might mitigate harm to patients when misleading information is presented to medical students.

\section{Box 2 Could this happen at other institutions?}

- Are conflict of interest disclosures left to individual instructors? Or are they made in a transparent and verifiable manner such as in an online repository?

- Are members of industry speakers bureau members involved in medical education? Or are they prohibited?

- Is public reporting of conflict of interest neglected by the policy? Or is it required by the policy?

- Are industry gifts to medical students allowed? Or are they prohibited?

- Are all industry payments handled by course organisers? Or are they administered independently of course organisers?

- Is the term 'unrestricted educational grant' used in disclosure statements? Or is a neutral term such as 'funding' used?
Internationally harmonised policies and procedures for managing conflicts of interest should involve clear disclosure, independent oversight, education about conflicts of interest and transparent handling of identified problems. In high-risk situations such as education on controversial topics involving therapeutics, conflicts of interest should be closely monitored if they cannot be completely avoided.

Funding The author was supported by a Banting Postdoctoral Fellowship from the Canadian Institutes of Health Research.

\section{Competing interests None.}

Provenance and peer review Not commissioned; externally peer reviewed.

\section{Box 3 Handling identified problematic conflicts of} interest in undergraduate medical education

- Immediately disclose the problem to superiors within the institution

- Determine which trainees were probably affected, noting that similar sessions might have been delivered in previous years or to trainees at different levels of training

- Disclose the problem to the affected trainees in a timely fashion

- If patient care was, or might have been, affected, disclose the problem to patients and take steps to mitigate any harm to patients

- If other institutions are likely to be affected by a similar problem, disclose the problem to them

- Determine how the problem materialised with reference to institutional policies (ie, determine if policies were inadequate or if adequate policies were not implemented)

- If there was a delay in identifying the problem, determine why the problem was not identified sooner

- Determine how similar problems might be avoided in the future and make this public 
Open Access This is an Open Access article distributed in accordance with the Creative Commons Attribution Non Commercial (CC BY-NC 3.0) license, which permits others to distribute, remix, adapt, build upon this work non-commercially, and license their derivative works on different terms, provided the original work is properly cited and the use is non-commercial. See: http://creativecommons.org/ licenses/by-nc/3.0/

\section{REFERENCES}

1 International Committee of Medical Journal Editors. Obligation to register clinical trials. http://www.icmje.org/publishing_10register.html (accessed 2 May 2011).

2 International Committee of Medical Journal Editors. Toward more uniform conflict disclosures: the updated ICMJE conflict of interest reporting form. http://www.icmje. org/updated_coi.pdf (accessed 2 May 2011).

3 Campbell EG, Weissman JS, Ehringhaus S, et al. Institutional academic industry relationships. JAMA 2007;298:1779-86.

4 Ehringhaus SH, Weissman JS, Sears JL, et al. Responses of medical schools to institutional conflicts of interest. JAMA 2008;299:665-71.

5 Coombes R. The pharmaceutical industry is stepping in to fill the therapeutics void. BMJ 2009;338:a3179.

6 AMSA PharmFree Scorecard. 2009. Reston, VA: American Medical Student Association. http://amsascorecard.org/ (accessed 18 Mar 2011).

7 Furlan $A D$, Reardon $R$, Weppler C. Opioids for chronic noncancer pain: a new Canadian practice guideline. CMAJ 2010;182:923-30.

8 Chou R, Ballantyne JC, Fanciullo GJ, et al. Research gaps on use of opioids for chronic noncancer pain: findings from a review of the evidence for an American Pain Society and American Academy of Pain Medicine clinical practice guideline. J Pain 2009:10:147-5.

9 Paulozzi LJ, Budnitz DS, Xi Y. Increasing deaths from opioid analgesics in the United States. Pharmacoepidemiol Drug Saf 2006;15:618-27.

10 Warner M, Chen LH, Makuc DM. Increase in fatal poisonings involving opioid analgesics in the United States, 1999-2006. NCHS data brief, no 22. Hyattsville, MD: National Center for Health Statistics. 2009. http://www.cdc.gov/nchs/data/ databriefs/db22.pdf (accessed 3 Jun 2013).

11 Dhalla IA, Mamdani MM, Sivilotti MLA, et al. Prescribing of opioid analgesics and related mortality before and after the introduction of long-acting oxycodone. CMAJ 2009; 181:891

12 Dhalla IA, Persaud N, Juurlink DN. Facing up to the prescription opioid crisis. BMJ 2011:343:d5142.

13 Meier B. Move to restrict pain killers puts onus on doctors. New York Times. http:// www.nytimes.com/2010/07/29/business/29pain.html (accessed 18 Mar 2011).

14 Government of Ontario, Ontario's Narcotic Strategy. http://www.health.gov.on.ca/en/ public/programs/drugs/ons/ons faq.aspx (accessed 18 Mar 2011).

15 Van Zee A. The promotion and marketing of oxycontin: commercial triumph, public health tragedy. Am J Public Health 2009:99:221.

16 Canadian Guideline for Safe and Effective Use of Opioids for Chronic Non-Cancer Pain. http://nationalpaincentre.mcmaster.ca/opioid/cgop_b_app_b08.html (accessed 26 Mar 2013).

17 Knotkova H, Fine P, Portenoy R. Opioid rotation: The science and the limitations of the equianalgesic dose table. J Pain Symptom Manage 2010;38:426-39.

18 World Health Organization, Pain Relief Ladder. http://www.who.int/cancer/palliative/ painladder/en/ (accessed 18 Mar 2010).

19 Furlan AD, Sandoval JA, Mailis-Gagnon A, et al. Opioids for chronic noncancer pain: a meta-analysis of effectiveness and side effects. CMAJ 2006;174:1589-94.

20 Jovey R. ed. Managing pain: the Canadian healthcare professional's reference. Toronto: Healthcare \& Financial Publishing, 2002

21 Jovey R. ed. Managing pain: the Canadian healthcare professional's reference. Stittsville: Baker Edwards Consulting Inc, 2008. External Review Report. University of Toronto Centre for the Study of Pain.
22 http://www.utoronto.ca/pain/uploads/files/UTCSP\%20External\%20Review\%20Report \%202008.pdf (accessed 18 Mar 2013).

23 Report on the Informal Inquiry into Concerns Raised about the University of Toronto's Interfaculty Pain Curriculum. http://www.facmed.utoronto.ca/Assets/ FacMed+Digital+Assets/Faculty+of+Medicine+1/FacMed+Digital+Assets/Leadership/ Final+Report+from+the+IPC+Informal+Inquiry+Dec+6th+2010.pdf (accessed 3 Jun 2013).

24 Ziegler $M G$, Lew $P$, Singer $B C$. The accuracy of drug information from pharmaceutical sales representatives. JAMA 1995;273:1296-8.

25 Sierles FS, Brodkey AC, Cleary LM, et al. Medical students' exposure to and attitudes about drug company interactions: a national survey. JAMA 2005:294:1034-42.

26 Hodges B. Interactions with the pharmaceutical industry: experiences and attitudes of psychiatry residents, interns and clerks. CMAJ 1995;153:553-9.

27 Strang D, Gagnon M, Molloy W, et al. National survey of the attitudes of Canadian physicians towards drug-detailing by pharmaceutical representatives. Ann $R$ Coll Physicians Surg Can 1996;29:474-8.

28 Vinson DC, McCandless B, Hosokawa MC. Medical students attitudes toward pharmaceutical marketing: possibilities for change. Fam Med 1993;25:31-3.

29 Kao AC, Braddock C 3rd, Clay M, et al. Effects of educational interventions and medical school policies in medical students' attitudes toward pharmaceutical marketing practices: a multi-institutional study. Acad Med 2011;86:1454.

30 Wilkes MS, Hoffman JR. An innovative approach to educating medical students about pharmaceutical promotion. Acad Med 2001:76:1271-7.

31 Sessions SY, Detsky AS. Incorporating economic reality into medical education. JAMA 2010:304:1229-30.

32 Sandberg WS, Carlos R, Sandberg EH, et al. The effect of educational gifts from pharmaceutical firms on medical students' recall of company names or products. Acad Med 1997;72:916-18.

33 AAMC. The scientific basis of influence and reciprocity: a symposium. 2007. www.aamc.org/publications (accessed 18 Mar 2011).

34 Wazana A. Physicians and the pharmaceutical industry: is a gift ever just a gift? JAMA 2000;283:373-80.

35 Gagnon M-A, Lexchin J. The cost of pushing pills: a new estimate of pharmaceutical promotion expenditures in the United States. PLoS Med 2008:5:e1.

36 Canadian Medical Association. Guidelines for physicians in Interactions with industry. http://policybase.cma.ca/dbtw-wpd/Policypdf/PD08-01.pdf (accessed 18 Mar 2011).

37 AAMC. Industry Funding of Medical Education, 2008. www.aamc.org/publications (accessed 18 Mar 2011).

38 Stanford University School of Medicine, Conflict of Interest Policy. http://med. stanford.edu/coi/siip/policy.html (accessed 17 Mar 2013).

39 Institute of Medicine. Conflict of interest in medical research, education, and practice. Washington, DC: National Academies Press, 2009 (accessed 17 Mar 2013, at http://www.iom.edu/CMS/3740/47464/65721.aspx.)

40 Propublica. http://projects.propublica.org/docdollars/ (accessed 18 Mar 2011).

41 Austad KE, Kesselheim AS. Conflict of interest disclosure in early education of medical students. JAMA 2011;306:991.

42 Loewenstein G, Sah S, Cain DM. The unintended consequences of conflict of interest disclosure. JAMA 2012;307:669-70.

43 U.S. Food and Drug Administration, Results of Investigation Into Illegal Promotion of OxyContin by The Purdue Frederick Company, Inc. http://www.fda.gov/ NewsEvents/Newsroom/PressAnnouncements/2007/ucm108913.htm (accessed 18 Mar 2010).

44 District Court for the Western District of Virginia, Agreed Statement of Facts. http://i. bnet.com/blogs/purdue-agreed-facts.pdf (accessed 18 Mar 2011).

45 Hébert PC, Levin AV, Robertson G. Bioethics for clinicians: 23. Disclosure of medical error. CMAJ 2001;164:509-13. 